\title{
Influence of the Forcing Process on Some Qualitative Aspects in Radicchio "Rosso di Treviso Tardivo" (Cichorium Intybus L., Group Rubifolium). 2. Antioxidant Capacity, Phenols and Ascorbic Acid
}

\author{
Carlo Nicoletto*, Ferdinando Pimpini \\ Department of Environmental Agronomy and Crop Science, Agripolis - University of Padova \\ Viale dell'Università 16, 35020 Legnaro (PD), Italy
}

Received: 11 June 2009. Accepted: 21 October 2009.

\begin{abstract}
There is currently a great deal of interest in phytochemicals as bioactive components of food, especially antioxidant compounds that could benefit human health. Radicchio "Rosso di Treviso tardivo" (Cichorium intybus L., group rubifolium) is a vegetable with high antioxidant properties, but nothing is known about antioxidant compounds changes during the forcing process. The experiment was conducted in Veneto (north-eastern Italy, $45^{\circ} 36^{\prime} \mathrm{N} ; 12^{\circ} 10^{\prime} \mathrm{E}$ ) with plants grown in a loamy soil and analyzed at harvest and during the forcing process $(0-10$ and 20 forcing daysFD). Results showed that the antioxidant capacity (AOC), phenols and ascorbic acid contents of this chicory decreased with different intensity during the forcing process. The outer inedible leaves displayed high AOC, which could provide phenolic extracts that could be used as natural antioxidants or to functionalize foods. The properties verified so far mean that this chicory can be considered an interesting and healthy vegetable for the consumer, also after the forcing process.
\end{abstract}

Key-words: chicory, forcing times, plant parts, leaf portions, quality, functional foods.

\section{Introduction}

There has been an increasing interest in the characterization of antioxidant phytochemicals due to their distinct bioactive properties (Dillard and German, 2000; Shetty and McCue, 2003). Antioxidants scavenge reactive oxygen species (ROS) that can cause cell damage in tissues. ROS are generated in normal metabolic processes as by-products of cell metabolism (Reyes et al., 2007). Fruits and vegetables contain antioxidant compounds like phenols and ascorbic acid that are known to reduce oxidative stress and prevent chronic diseases (Diaz et al., 1997; Giacosa et al., 1997; Miller et al., 1998; Vinson et al., 1998; Papetti et al., 2006). The antioxidant properties of these compounds are responsible for their anticancer, antiviral and anti-inflammatory actions (Cao et al., 1997). The usefulness of knowing how each food can contribute to the total antioxidant action of dietary antiradicals is clear. For this reason, a number of studies have been carried out in recent years to identify and characterize different vegetables that could help our organism to combat ROS. Among these, some studies were conducted on radicchio (Cichorium intybus L., group rubifolium), especially on cv "Rosso di Chioggia" (Innocenti et al., 2005; Ninfali et al., 2005; Papetti et al., 2006; Francke and Majkowska-Gadomska, 2008; Lavelli, 2008). Radicchio has been regarded for many years (Pimpini, 1990; Lavelli, 2008) as a food source of nutritionally relevant phytochemicals and its potential health benefits have been related to its phenolic compounds (Innocenti et al., 2005). Radicchio "Rosso di Treviso tardivo" has been less studied from a

\footnotetext{
* Corrisponding Author: Tel.: +39 0498272826; Fax: +39 0498272839. E-mail address: carlo.nicoletto@unipd.it
} 
qualitative point of view because it is more rarely cultivated. This is mainly due to the onerous forcing process this chicory requires after harvest to achieve its high qualitative and aesthetic level. Recent studies (Innocenti et al., 2005) considered this chicory only at the end of forcing process when the head is marketable and ready for the consumer. No investigations have been done on antioxidant changes during the forcing process. In a previous paper (Nicoletto and Pimpini, 2009), radicchio "Rosso di Treviso tardivo" was investigated to assess the content of hazardous nitrogen compounds during the forcing process. A very low content of nitrates and nitrites was demonstrated, so radicchio "Rosso di Treviso tardivo" can be considered a healthy vegetable from that point of view. The objective of this research was to evaluate other positive characteristics of this chicory, with attention being focused on determining changes of some antioxidant compounds such as phenols, ascorbic acid and antiradical activity during the forcing process.

\section{Materials and methods}

\section{Cropping conditions and plant material}

The experiment was conducted in 2007-2008 at Zero Branco (Treviso province, north-eastern Italy, $45^{\circ} 36^{\prime} \mathrm{N}$; $12^{\circ} 10^{\prime} \mathrm{E}$ on a loamy soil (sand $36 \%$, silt $38 \%$ and clay $26 \%$ ). The main crop management practices and dates are reported in Table 1 . Three plots $25 \mathrm{~m} 2(5 \times 5 \mathrm{~m})$ were singled out and 35 representative plants were uprooted from each of these at harvest time. After harvest and before starting the forcing process ( 0 forcing days $-0 \mathrm{FD})$, the qualitative characteristics were evaluated on a sample of 5 plants. The remaining plants, with their taproot cut at $0.20-0.25 \mathrm{~m}$, were gathered together in two bundles (15 plants each) and placed in a tank in a dark room for the forcing process. Well water at $11-13{ }^{\circ} \mathrm{C}$ was fed continuously into the tank from one side and, after reaching the level of the plant stem bases, flowed out from the opposite side. This technique maintained the required temperature at root level. Qualitative analyses were performed on 5 plants midway (10 FD) and at the end of the forcing process (20 FD). This gave a total of 3 sampling times (0, 10 and $20 \mathrm{FD})$.

Each plant was divided into five parts as follows: leaves were removed from stem, washed and dried, then separated into outer, intermediate and inner leaves (head), stem and roots were also considered. The leaves were cut in half along the midrib in order to have two mirror parts to use: a) to create a whole leaf sample; b) to separate veins from leaf blade. Similar parts from each plant were put together and mixed to give a homogeneous sample. A total of 11 plant parts were obtained: outer (1), intermediate (2) and inner (3) leaves, stem (4) and roots (5), outer (6), intermediate (7) and inner (8) leaf blades, outer (9), intermediate (10) and inner (11) veins.

\section{Meteorological data}

Temperature, relative humidity $(\mathrm{RH})$ and rainfall data during the experiment period and multiyear data (1992-2007) were collected at the ARPAV (Veneto-Territory Safety Department) meteorological station in Zero Branco (Fig. 1).

Table 1. Crop management practices during the experiment.

\begin{tabular}{lcc}
\hline Crop management practices & Dates & Notes \\
\hline Fertilization & $3 / 7 / 07$ & $0.13 .26+3 \mathrm{Mg}+0.2 \mathrm{~B}\left(500 \mathrm{~kg} \mathrm{ha}^{-1}\right)$ \\
Seed origin & & self-produced \\
Field sowing & $6 / 7 / 07$ & \\
Emergence & $16 / 7 / 07$ & volume $100 \mathrm{~m}^{3} \mathrm{ha}^{-1}$ \\
Irrigations & $8-10-12-14-16 / 7 / 07$ & sprinkling \\
Irrigation method & $10 / 8 / 07$ & \\
Thinning & $30 / 8 / 07$ & inter row tillage \\
Cultivation & $20 / 11 / 07$ & uprooting \\
Harvest & & 25 \\
Plot area $\left(\mathrm{m}^{2}\right)$ & & $0.45 \mathrm{x} 0.30$ \\
Distance between plants $(\mathrm{m})$ & & 7.4 \\
Plant density (plants $\left.\mathrm{m}^{-2}\right)$ & &
\end{tabular}



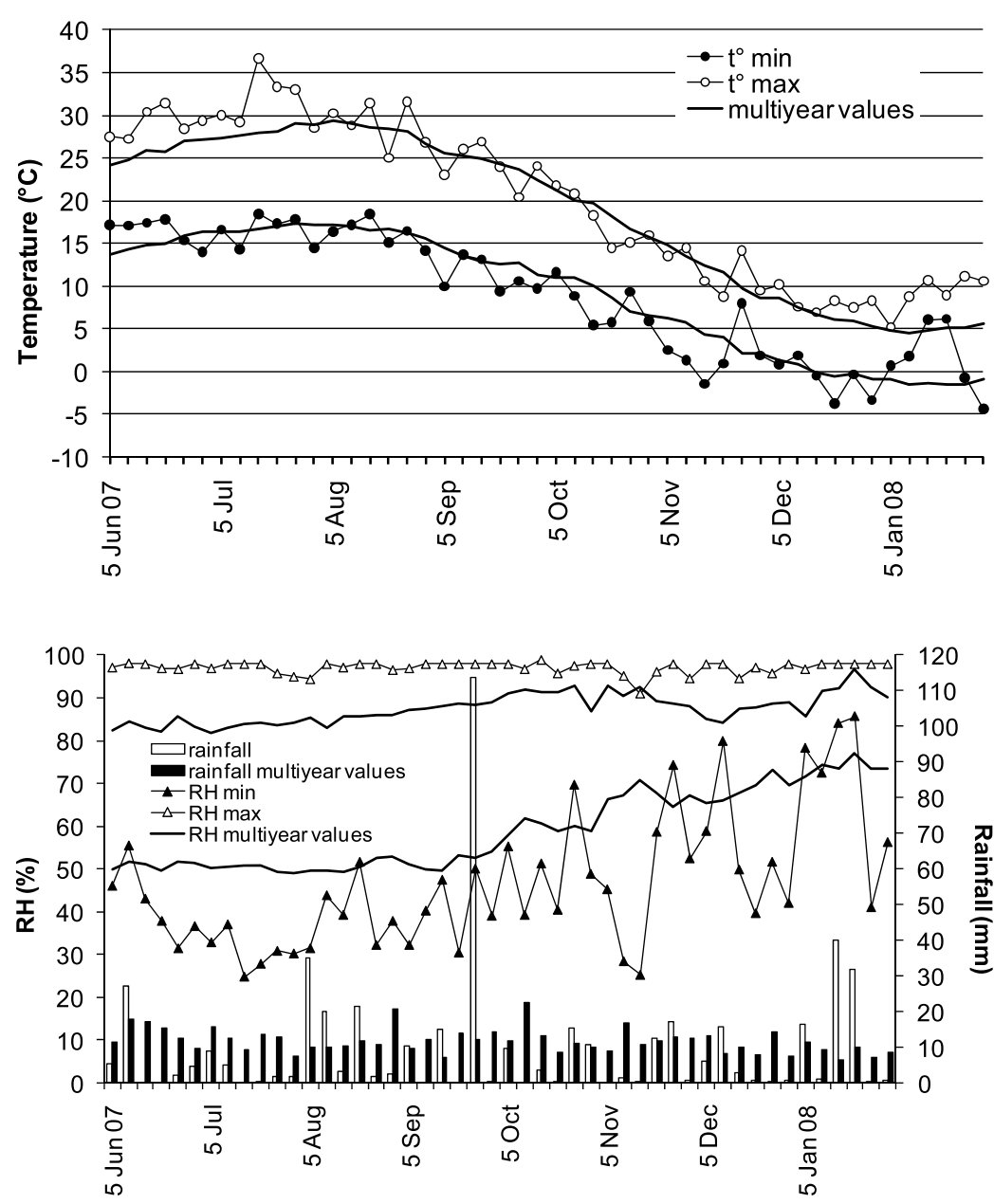

Figure 1. Five-day averages of maximum and minimum temperatures $\left({ }^{\circ} \mathrm{C}\right)$ recorded during the experiment and multiyear values (1992-2007).

Figure 2. Five-day averages of maximum and minimum relative humidity and five-day cumulative rainfall recorded during the experiment and multiyear values (1992-2007).
The values of max temperature recorded during the experiment were very different from the multiyear data in June and July, being even more than $10{ }^{\circ} \mathrm{C}$ higher during the first half of July. There were then no relevant variations until the first half of December; after this period $\mathrm{t}^{\circ}$ max was always higher than the multiyear data. Min $t^{\circ}$, after an initial variation in the first 20 days of June, stayed around the multiyear values till 25th August. Then from 25 ${ }^{\text {th }}$ August to $5^{\text {th }}$ January 2008, except for the period from $5^{\text {th }}$ to $10^{\text {th }}$ September, on the $5^{\text {th }}$ and $25^{\text {th }}$ October, $25^{\text {th }}$ November and $10^{\text {th }}$ December, values were always lower than the multiyear data. In the last period of the crop cycle, similarly to max $\mathrm{t}^{\circ}$, increasing temperatures were recorded till $25^{\text {th }}$ January 2008. Total rainfall recorded during the experimental period was $465.8 \mathrm{~mm}$ (Fig. 2), $16.7 \%$ lower than the multiyear values (559.0 $\mathrm{mm})$. There were particularly heavy rainfall events during the first 20 days of August. The amount and rainfall distribution obviously influenced RH trend (Fig. 2). RH max values recorded during the experiment, except for $15^{\text {th }}$ November, were always higher than the multiyear data. RH min was always lower than the expected values, except for $10^{\text {th }}$ June, $20^{\text {th }} \mathrm{Au}$ gust, $25^{\text {th }}$ November, $5^{\text {th }}$ December and early January.

\section{Chemicals and reagents}

Anhydrous iron (III) chloride, acetic acid (glacial) and ammonium iron (II) sulfate hexahydrate, ascorbic acid and xylenes were purchased from Honeywell Riedel-de Haën (Hanover, Germany). Gallic acid monohydrate, 2,4,6-tripyridyl-2-triazine (TPTZ), 2,6-dichlorophenolindophenol and meta-phosphoric acid were obtained from Fluka (Germany); methanol from VWR Prolabo (France), Folin-Ciocal- 
teau's reagent from Labochimica (Padova, Italy) and anhydrous sodium acetate was purchased from Sigma-Aldrich (Italy). All reagents were of analytical grade.

\section{Extraction of total phenols and total antioxidant activity}

Radicchio samples were frozen and stored at $-80{ }^{\circ} \mathrm{C}$ before proceeding with the analysis. A quantity of $5 \mathrm{~g}$ of tissue was whisked in $20 \mathrm{~mL}$ of methanol with Ultra Turrax T25 until uniform consistency at $13500 \mathrm{rpm}$. This was filtered (589 Schleicher filter paper) and the solution used for the determination of antioxidant activity and total polyphenols.

\section{Determination of total phenols}

Total phenols were estimated using the Folin-Ciocalteau method (Singleton and Rossi, 1965). 1000 $\mu \mathrm{L}$ of Folin-Ciocalteau's phenol reagent and a sample volume of $200 \mu \mathrm{L}$ were added to $2000 \mu \mathrm{L}$ of deionised water and accurately mixed. After 1 min and before $8 \mathrm{~min}, 800 \mu \mathrm{L}$ of $20 \%$ sodium carbonate solution was added, the solution was thoroughly mixed and total phenols were estimated spectrophotometrically (Shimadzu UV-1800) at $765 \mathrm{~nm}$. All tests were conducted in triplicate and averaged. The concentration of polyphenols in samples was derived from a standard curve of gallic acid ranging from 0 to $600 \mu \mathrm{g} \mathrm{mL} \mathrm{mL}^{-1}$ (Correlation coefficient: $\left.\mathrm{R}^{2}=0.9994\right)$.

Determination of total antioxidant activity by Ferric Reducing Antioxidant Power

The assay was based upon the methodology of Benzie and Strain (1996). The Ferric Reducing Antioxidant Power (FRAP) reagent was prepared fresh so that it contained $1 \mathrm{mM} 2,4,6-$ tripyridyl-2-triazine (TPTZ) and $2 \mathrm{mM}$ ferric chloride in $0.25 \mathrm{M}$ sodium acetate at $\mathrm{pH}$ 3.6. A $50 \mu \mathrm{L}$ aliquot of the methanol extract prepared as above was added to $3950 \mu \mathrm{L}$ of FRAP reagent, and mixed. After leaving the mixture at $20{ }^{\circ} \mathrm{C}$ for $4 \mathrm{~min}$, the absorbance at $593 \mathrm{~nm}$ was determined. Calibration was against a standard curve $\left(0-1200 \mu \mathrm{g} \mathrm{m \textrm {m } ^ { - 1 }}\right.$ ferrous ion) produced by the addition of freshly prepared ammonium ferrous sulfate. FRAP values were calculated as $\mu \mathrm{g} \mathrm{mL}^{-1}$ ferrous ion (ferric reducing power) from three determinations and are presented as mg kg-1 of FeE (ferrous ion equivalent).

\section{Extraction and determination of ascorbic acid}

Samples were frozen and stored at $-80{ }^{\circ} \mathrm{C}$ before proceeding with the analysis. Five-gram samples were homogenized until uniform consistency in a meta-phosphoric acid and acetic acid solution. Ascorbic acid was determined following the ISO 6557 method.

\section{Statistical analysis}

Statistical analysis (ANOVA) was performed considering the five main plant parts from (1) to (5), which were factorially combined with 3 forcing days $(0,10$ and $20 \mathrm{FD})$ to obtain 15 treatments. When we refer to whole plant, values were obtained from the weighted average of 5 fractions.

Two leaf parts values (leaf blade and vein) were factorially combined with 3 leaf positions (outer, intermediate and inner) and with 3 forcing periods $(0,10$ and $20 \mathrm{FD})$ to obtain 18 theses. Because of whole leaf dependence these data were elaborated separately.

Averages were separated with Tukey's HSD test.

\section{Results}

\section{Weight variations}

During the forcing process (Fig. 3), only outer leaves showed a relevant weight reduction of $89.0 \%$. Other plant parts instead displayed a general increase of this parameter although with different intensity. In fact, after the forcing process, inner leaves (head) exhibited the high-

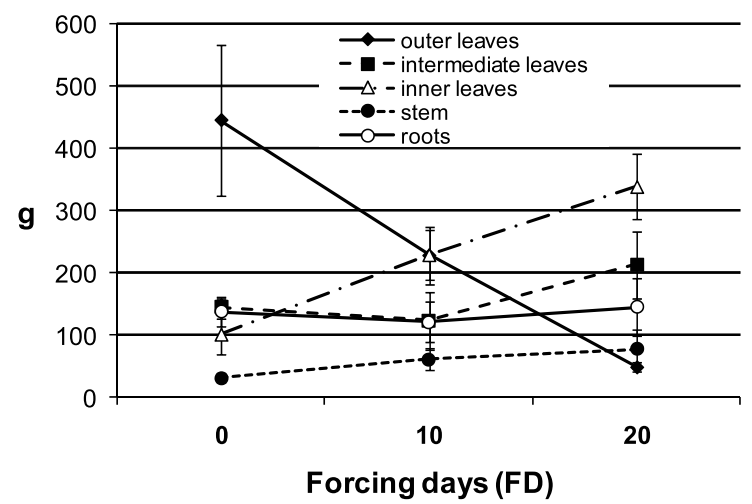

Figure 3. Different influence of forcing days (FD) on plant parts fresh weight $(\mathrm{g})$.

Interaction "plant parts $\mathrm{x}$ forcing days" significant at $\mathrm{P} \leq 0.01$. Vertical bars indicate standard error. 
Table 2. Effects of plant parts and forcing days on some qualitative traits of radicchio during the forcing process.

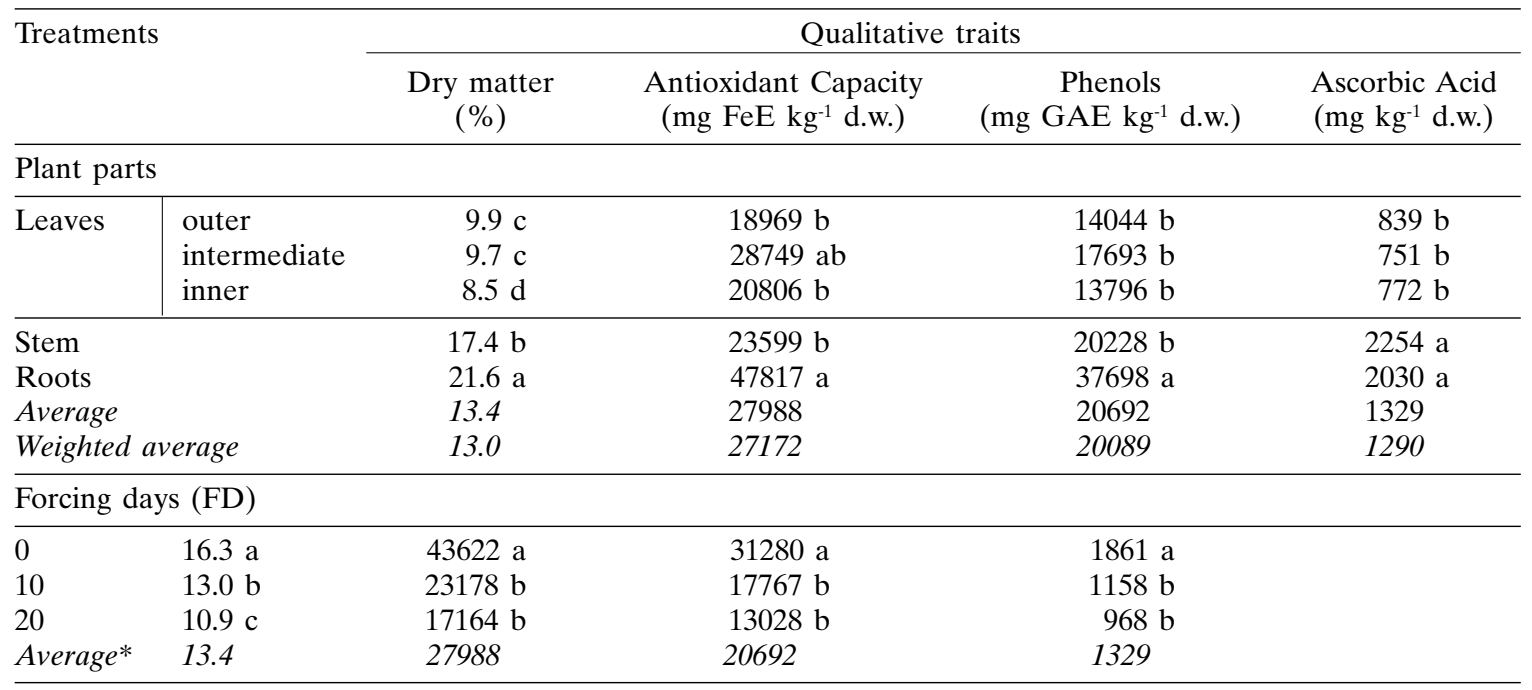

* Average of three forcing times 0-10-20 FD.

Within plant parts and forcing days, column values with no letter in common differ significantly at $\mathrm{P} \leq 0.01$ (Tukey HSD test).

est weight increase of $70.0 \%$. Stem, similarly to other plant parts, had a lower weight gain $(60.3 \%)$ than the head; roots and intermediate leaves, after an initial and slight weight reduction, increased their values over the next $10 \mathrm{FD}$ by $17.8 \%$ and $73.3 \%$ respectively.

\section{Dry matter}

During the forcing process a general dry matter percentage decrease of the whole plant was observed (Tab. 2). Values varied from $14 \%$ at harvest (0 forcing days - FD) to $8.2 \%$ at $20 \mathrm{FD}$. Roots had the highest dry matter percentage $(21.6 \%)$, followed by stem $(17.4 \%)$, outer, intermediate and inner leaves $(9.9,9.7$ and $8.5 \%$ respectively).

Interesting dry matter content variations occurred in different plant parts during the forcing process ("interaction plant parts $\mathrm{x}$ forcing days"). The leaves (Fig. 4A) belonging to the head showed the highest dry matter percentage reduction from $11.8 \%(0 \mathrm{FD})$ to $6.0 \%$ (20 FD); for outer leaves, instead, the decrease was limited to $2.9 \%$. Roots and stem had gradual reductions of 5.5 and $8.4 \%$ respectively.

Comparison of leaf blades and veins (Tab. 3) showed the higher concentration for the former and for all leaf positions, with an average increase of $49.0 \%$. The significance of the interaction "leaf parts x leaf position" is justified by the different intensity of responses, with a con- sistent decrease $(41.0 \%)$ from 0 to $20 \mathrm{FD}$ and from outer to inner leaves $(8.3 \%)$ being observed. The interaction "forcing days $x$ leaf position" was also due to the different intensity of response. For all leaf blades (Fig. 5A) there was a considerable decrease in dry matter, from $18.0 \%$ to $10.0 \%$, between 0 and $10 \mathrm{FD}$; from 10 to 20 FD only outer and inner leaf blades showed a further dry matter reduction of 1.9 and $0.4 \%$ respectively. There were small reductions during the forcing process for outer and intermediate veins, while relevant differences were shown by inner leaf veins $(4.2 \%)$.

\section{Antioxidant Capacity}

As table 2 shows, during the forcing process the weighted average Antioxidant Capacity (AOC) of the whole plant decreased from $43622 \mathrm{mg}$ FeE kg-1 dry weight (d.w.) (2676 mg FeE kg-1 fresh weight (f.w.)) at harvest to $17164 \mathrm{mg} \mathrm{FeE}$ $\mathrm{kg}^{-1}$ d.w. (1574 $\mathrm{mg} \mathrm{FeE} \mathrm{kg}^{-1}$ f.w.) at $20 \mathrm{FD}$, i.e. $60.6 \%$ in d.w. and $41.2 \%$ in f.w. The main effect of plant parts highlighted that higher AOC was found in roots (47817 mg FeE kg-1 d.w.) followed by intermediate leaves (28749 $\mathrm{mg} \mathrm{FeE} \mathrm{kg}^{-1}$ d.w.). Values expressed by whole intermediate leaves did not differ statistically from stem, inner and outer leaves. Trends of AOC differed for the whole plant (interaction "plant parts x forcing days") (Fig. 4B). In fact for whole leaves there was a general contraction in values during first 

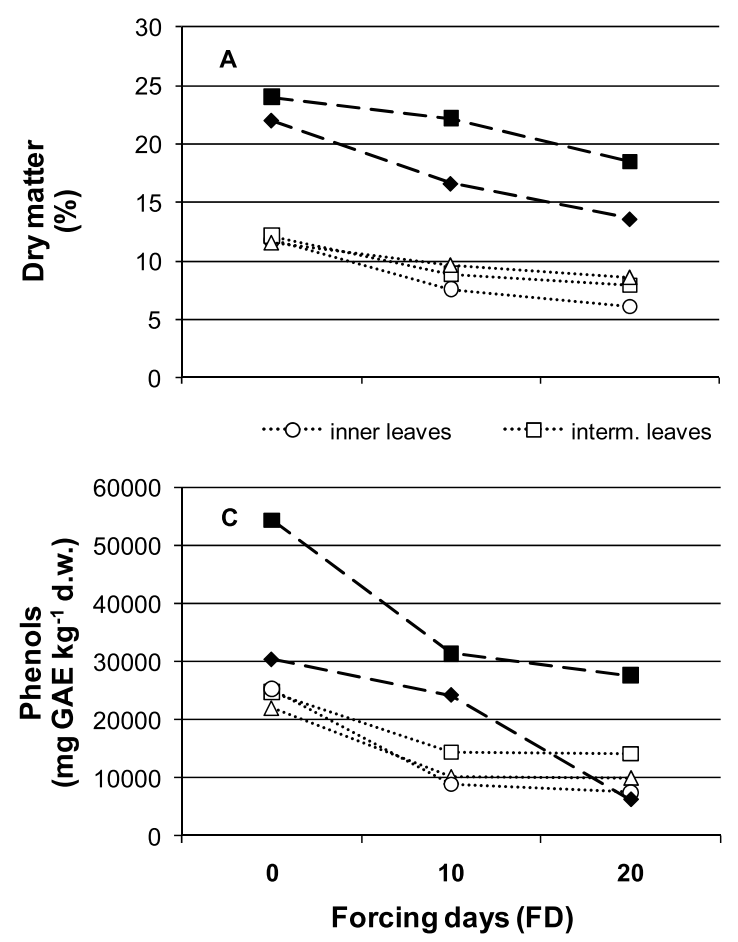
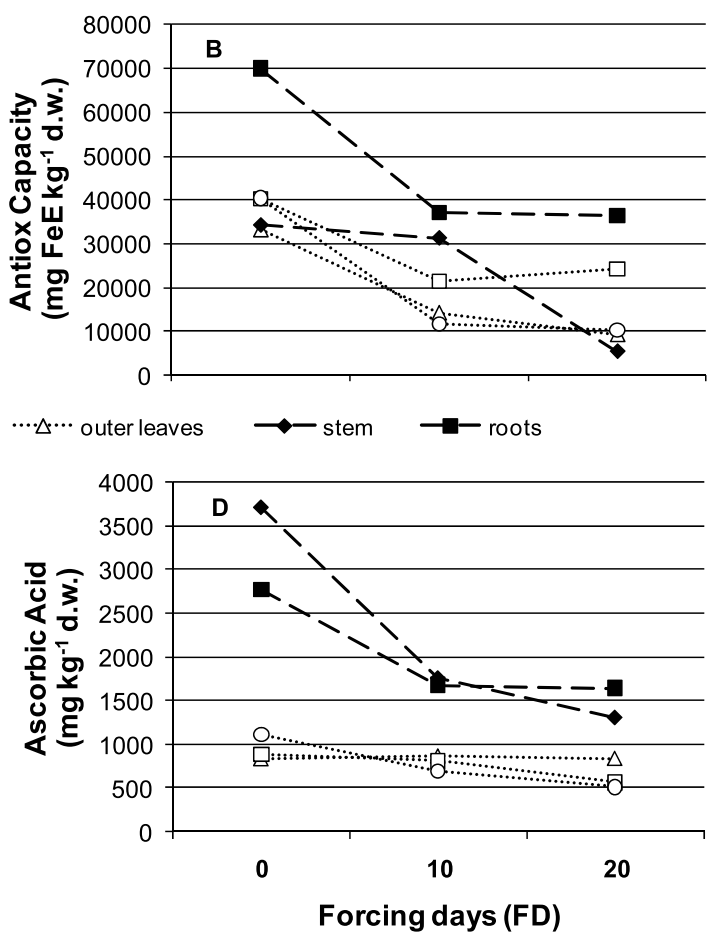

Figure 4. Different influence of forcing days on dry matter (A), antioxidant capacity (B), phenols (C) and ascorbic acid (D) in plant parts.

All interactions $(\mathrm{A}, \mathrm{B}, \mathrm{C}, \mathrm{D})$ significant at $\mathrm{P} \leq 0.01$.

10 FD that, except for intermediate leaves, continued until the end of the forcing process. Roots, differently from stem, drastically decreased by $46.9 \%$ during the first 10 FD to stay around $37000 \mathrm{mg} \mathrm{FeE} \mathrm{kg}^{-1}$ d.w. until $20 \mathrm{FD}$.

Concerning leaf parts (Tab. 3), leaf blades always showed higher AOC. The average increase compared to leaf veins was $87.7 \%$. As regards the main effect of forcing days and leaf positions, in the first case a values contraction from 0 to $20 \mathrm{FD}$ was observed; in the second, outer leaves displayed the higher AOC going over $50000 \mathrm{mg} \mathrm{FeE} \mathrm{kg}^{-1}$ d.w. In relation to different effect of leaf position and forcing periods, AOC decreased from 0 to 20 FD for all leaf positions, although with different intensity. For leaf blades (Fig. 5B), higher AOC was observed in those outer at $0 \mathrm{FD}$ (175768 mg FeE kg-1 d.w.) followed by inner and intermediate. Afterwards their content considerably decreased, reaching values from $47617 \mathrm{mg} \mathrm{FeE} \mathrm{kg}{ }^{-1}$ d.w. for intermediate leaf blades to $35412 \mathrm{mg} \mathrm{FeE} \mathrm{kg}{ }^{-1}$ d.w. for outer ones at the end of forcing process. Leaf veins showed lower values than blades throughout the forcing process, always remaining under $20000 \mathrm{mg} \mathrm{FeE} \mathrm{kg}^{-1}$ d.w.

\section{Total phenols}

Phenols content (Tab. 2) decreased by 58.3\% from 0 to 20 FD. Concerning plant parts, higher concentration was observed in roots $(37698$ mg GAE kg-1 d.w.), while other plant parts did not statistically differ with values of between 20228 (stem) and 13796 (inner leaves) mg GAE $\mathrm{kg}^{-1}$ d.w. Different responses were expressed during the forcing process (interaction "plant parts $\mathrm{x}$ forcing days") (Fig. 4C). In fact, leaves values decreased by $65.0 \%, 53.8 \%$ and $41.6 \%$ in the first $10 \mathrm{FD}$ for inner, outer and intermediate leaves respectively. Only the intermediate leaves then showed a slight increase from 10 to $20 \mathrm{FD}$, while the others continued to decrease till the end of forcing process. Roots and stem displayed a trend similar to AOC in which roots, contrary to stem, decreased drastically $(42.3 \%)$ from 0 to $10 \mathrm{FD}$ and slightly $(11.8 \%)$ from 10 to $20 \mathrm{FD}$.

As regards leaf parts (Tab. 3), leaf blades 
Table 3. Effects of forcing days, leaf position and leaf parts on some qualitative traits of radicchio.

\begin{tabular}{|c|c|c|c|c|c|c|}
\hline \multirow[t]{2}{*}{ Leaf position } & \multicolumn{3}{|c|}{ Forcing days (FD) } & \multicolumn{2}{|c|}{ Leaf parts } & \multirow[t]{2}{*}{ Average } \\
\hline & 0 & 10 & 20 & blades & veins & \\
\hline \multicolumn{7}{|c|}{ Dry matter $(\%)$} \\
\hline Outer & 14.0 & 9.8 & 8.5 & 12.3 & 9.2 & $10.8 a$ \\
\hline Intermediate & 13.9 & 9.3 & 8.8 & 12.7 & 8.6 & $10.7 a$ \\
\hline Inner & 13.8 & 8.4 & 7.5 & 12.4 & 7.4 & $9.9 b$ \\
\hline Average & $13.9 \mathrm{a}$ & $9.2 \mathrm{~b}$ & $8.2 \mathrm{c}$ & $12.5 \mathrm{~A}$ & $8.4 \mathrm{~B}$ & \\
\hline \multicolumn{7}{|c|}{ Antioxidant Capacity (mg FeE kg-1 d.w.) } \\
\hline Outer & 94923 & 38193 & 22421 & 92481 & 11210 & $51846 a$ \\
\hline Intermediate & 52393 & 33114 & 28052 & 65723 & 9983 & $37853 b$ \\
\hline Inner & 77487 & 26403 & 22616 & 76713 & 7624 & $42169 a b$ \\
\hline Average & 74934 a & $32570 \mathrm{~b}$ & $24363 \mathrm{~b}$ & 78306 A & 9606 B & \\
\hline \multicolumn{7}{|c|}{ Phenols (mg GAE kg-1 d.w.) } \\
\hline Outer & 34560 & 15028 & 8555 & 30555 & 8207 & $19381 b$ \\
\hline Intermediate & 43909 & 19939 & 11552 & 42899 & 7368 & $25133 a b$ \\
\hline Inner & 52136 & 21465 & 11988 & 50703 & 6356 & $28530 a$ \\
\hline Average & $43535 \mathrm{a}$ & $18811 \mathrm{~b}$ & $10698 \mathrm{~b}$ & 41386 A & $7310 \mathrm{~B}$ & \\
\hline \multicolumn{7}{|c|}{ Ascorbic Acid (mg kg-1 d.w.) } \\
\hline Outer & 1284 & 877 & 859 & 1194 & 820 & $1007 a$ \\
\hline Intermediate & 1012 & 801 & 641 & 966 & 670 & $818 b$ \\
\hline Inner & 1293 & 716 & 564 & 1164 & 551 & $858 a b$ \\
\hline Average & 1197 a & $798 \mathrm{~b}$ & $688 \mathrm{~b}$ & $1108 \mathrm{~A}$ & $680 \mathrm{~B}$ & \\
\hline
\end{tabular}

Within forcing days (lower-case letters), leaf position (letters in italics) and leaf parts (capital letters), values with no letter in common differ significantly at $\mathrm{P} \leq 0.01$ (Tukey HSD test).

were significantly different from veins with values $82.3 \%$ higher. Concerning leaf position effect, values increased from outer to inner leaf blades while an opposite trend was observed for veins. The main effect of forcing days showed higher concentration at harvest ( 0 FD) and that of leaf position showed increasing values shifting from outer to inner leaves. These two variables did not significantly interact. Figure 5C shows that inner leaf blades phenols content was higher than intermediate and outer ones. During the forcing process a relevant contraction was observed from 0 to 10 FD that continued at low intensity until the end of treatment. Roots and stem decreasing slightly and always remaining under $10000 \mathrm{mg}$ FeE $\mathrm{kg}^{-1}$ d.w. appeared not to be affected by the forcing process.

\section{Ascorbic Acid}

During the forcing process (Tab. 2) ascorbic acid (AA) content decreased from $1861 \mathrm{mg} \mathrm{kg}^{-1}$ d.w. (0 FD) to $968 \mathrm{mg} \mathrm{kg}^{-1}$ d.w. (20 FD). Regarding plant parts, roots and stem showed higher AA content (2254 and $2030 \mathrm{mg} \mathrm{kg}^{-1}$ d.w. respective- ly) followed by all leaves, which did not themselves significantly differ. Figure 4D shows that, except for outer leaves, AA decreased in all plant parts during the forcing process. Inner and intermediate leaves showed a slight decrease from 0 to $10 \mathrm{FD}$ while in roots and stem it was $39.6 \%$ and $52.8 \%$ respectively. In the latter half of the treatment (10-20 FD) all plant parts displayed a slight decrease of between $25.8 \%$ (stem) and $30.3 \%$ (intermediate leaves). The main effect of leaf parts (Tab. 3) showed statistically higher values for leaf blades than veins, which were repeated with different intensity depending on leaf position. For forcing days and leaf position main effect, in the first case, a decrease of AA was observed from 0 to $20 \mathrm{FD}$, in the second one, outer leaves displayed higher values followed by inner and intermediate. These two variables significantly interacted, as reported in Table 3. Figure 5D shows that for all leaf blades AA content relevantly decreased in the first $10 \mathrm{FD}$, from 10 to $20 \mathrm{FD}$, instead, contrary to inner and intermediate, AA content in outer leaf blades slightly increased $(8.0 \%)$. At 

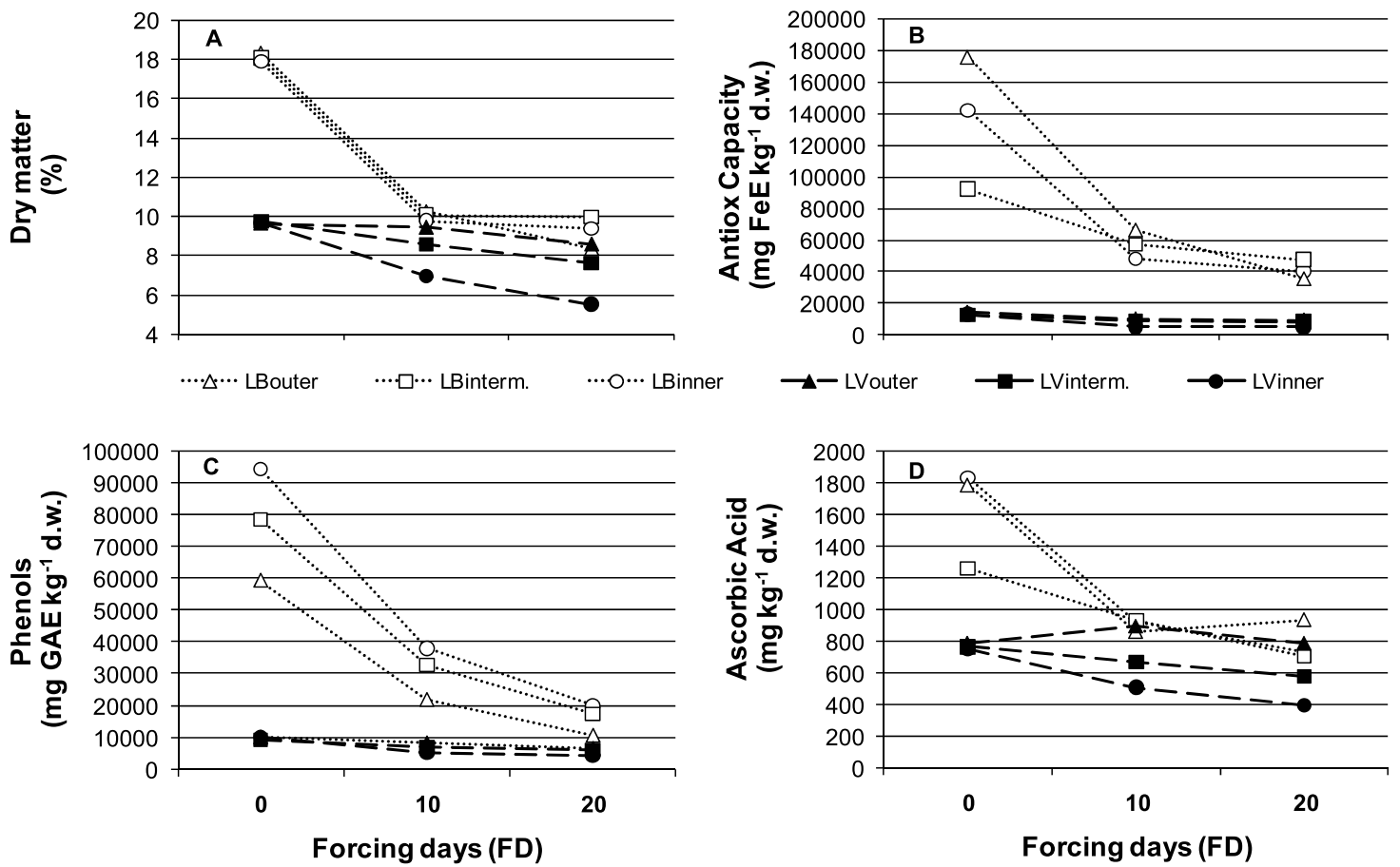

Figure 5. Different influence of forcing days on dry matter (A), antioxidant capacity (B), phenols (C) and ascorbic acid (D) in two leaf parts (leaf blades-LB, leaf veins-LV) at three positions (outer, intermediate and inner).

All interactions (A, B, C, D) significant at $\mathrm{P} \leq 0.01$.

harvest AA content was the same for all leaf veins, then intermediate and inner veins $\mathrm{AA}$ content gradually decreased until the end of the forcing process. Instead, outer veins increased to $892 \mathrm{mg} \mathrm{kg}^{-1}$ d.w. at $10 \mathrm{FD}$ then decreased to less than $800 \mathrm{mg} \mathrm{kg}^{-1}$ d.w. at $20 \mathrm{FD}$.

\section{Correlations}

Correlations were verified among some quality parameters. These elaborations were done for all plant parts, for the aerial ones and for the edible part only (inner leaves) (Fig. 6). The different phenolic contents of plant parts were positively and highly correlated with AOC (Fig. 6A, $\mathrm{B}$ and $\mathrm{C}$ ). In regard to AOC and ascorbic acid (Fig. 6D, E and F), $\mathrm{R}^{2}$ values increased moving from all plant parts (0.3023) to edible leaves only (0.9598). As for the relation between phenols and ascorbic acid contents (Fig. 6G, H and I), the $\mathrm{R}^{2}$ value for all plant parts was 0.4560 and reached 0.9671 considering only the inner leaves.

Other correlations were performed considering also some previously studied $\mathrm{N}$ compounds (Nicoletto and Pimpini, 2009), but their
$\mathrm{R}^{2}$ values were barely or not significant (correlations considering all plant parts: $\mathrm{NO}_{3}$, phenols (0.0038); $\mathrm{NO}_{2}$, phenols (0.0368); organic $\mathrm{N}$, phenols (0.1138); $\mathrm{NO}_{3}, \mathrm{AOC}(0.0036) ; \mathrm{NO}_{2}, \mathrm{AOC}$ (0.0766); organic $\mathrm{N}$, AOC (0.2041), $\mathrm{NO}_{3}$, ascorbic acid (0.2080); $\mathrm{NO}_{2}$, ascorbic acid (0.0010); organic $\mathrm{N}$, ascorbic acid (0.0014).

\section{Discussion and conclusions}

The fresh weight trend of plant parts during the forcing process highlighted the drastic decrease in outer leaves due to senescence processes during the treatment. However, the head fresh weight increased due to new leaves formation and the growth of younger leaves already present at harvest. The intermediate leaves, less affected by senescence than the outer ones, had a weight increase at the end of the forcing treatment due to their growth. Similar behavior was observed in the roots. In fact, after an early slight loss of weight caused by sugar contents allocated to new leaves formation, roots exhibited a slight weight increase thanks to new roots 


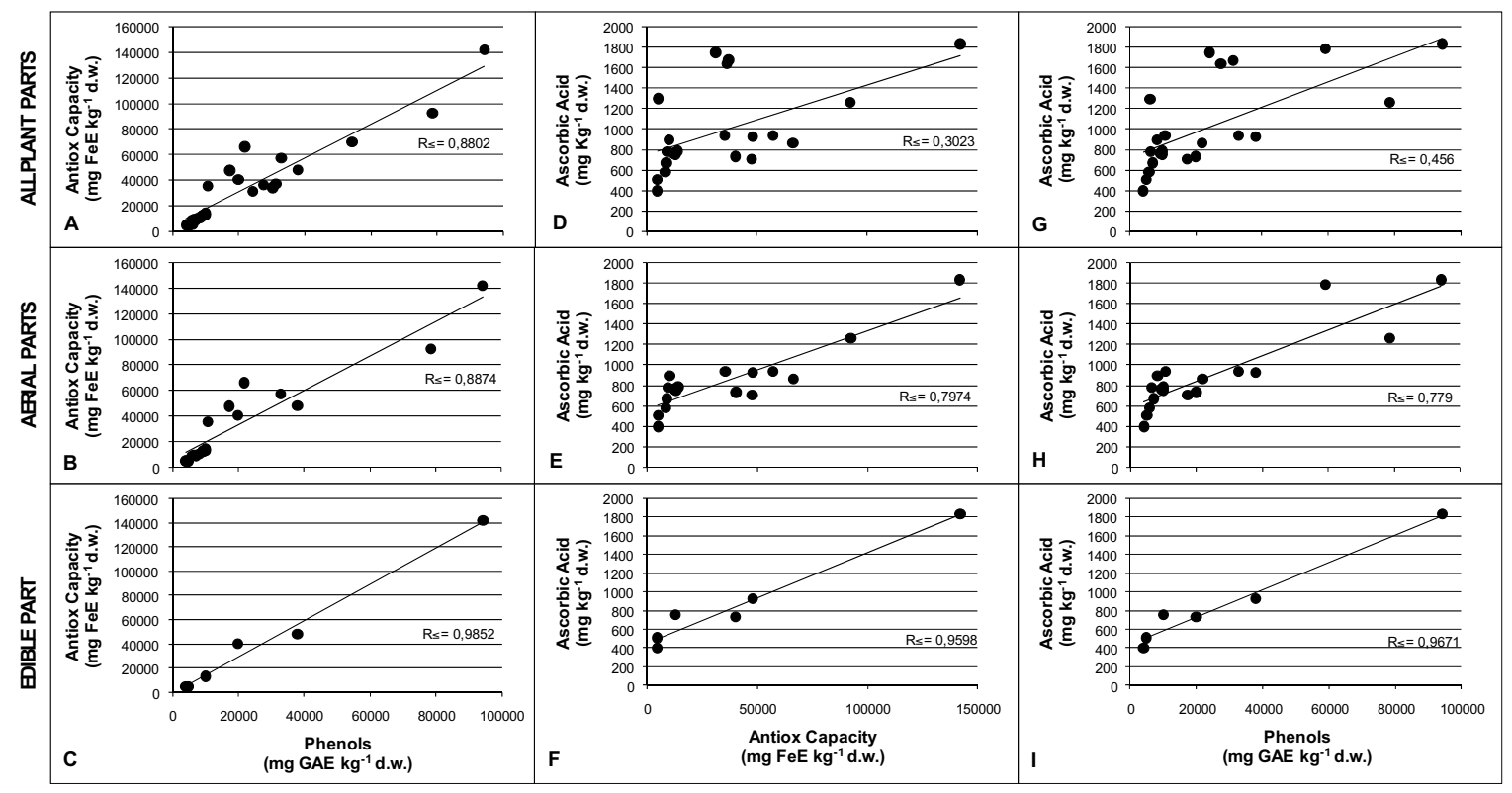

Figure 6. Correlations between phenols and antioxidant capacity, antioxidant capacity and ascorbic acid, phenols and ascorbic acid considering all plant parts (A, D and $\mathrm{G})$, only the aerial parts (B, E and $\mathrm{H})$ and only the edible part (C, F and I).

formation. Stem showed a continuous weight increase, probably attributable to its lengthening due to inner leaves growth.

This study measured the phenolic and ascorbic acid contents and antioxidant capacities of radicchio "Rosso di Treviso tardivo" at harvest and during the forcing process. Our data demonstrated a general decrease of antioxidant compounds during this process. This result mainly depends on external leaves loss due to their senescence. In fact this aerial part presented the higher AOC because of abiotic and biotic stresses during the growing cycle that enhanced antiradical activity (Shao Hong-bo et al., 2008). The first cause of abiotic stress for this chicory is frost. Low temperatures, which usually occur from November to February, are responsible for the typical red foliage color due to anthocyanic compounds that are a group of phenols (Mazza and Miniatti, 1993; Rice-Evans et al., 1997). These and other chemical components influence the total phenolic content of radicchio (Innocenti et al., 2005). After the forcing process the ascorbic acid content in radicchio "Rosso di Treviso tardivo" was similar to "Rosso di Chioggia" as reported by Francke and Majkowska-Gadomska (2008) and resulted comparable to or higher than other raw vegetables like carrot, garlic, red beetroot, potato, onion, celery etc. (Carnovale and Marletta, 2009). Regarding correlations, as reported by many authors for different species (Kang and Saltveit, 2002; Llorach et al., 2004; Reyes et al., 2005; Lavelli, 2008; Anesini et al., 2008), in this chicory the AOC has also been positively correlated with phenolic content and ascorbic acid is positively correlated with phenolic content and AOC.

In conclusion the data obtained prove that radicchio "Rosso di Treviso tardivo" presents high levels of health-promoting and antioxidant compounds. The outer inedible leaves displayed high AOC, which could provide phenolic extracts that could be used as natural antioxidants or to functionalize foods as has recently been reported for some species (Larrosa et al., 2002; Yamakawa and Yoshimoto, 2002; Stojceska et al., 2008). Further studies are needed to fully understand and identify the other antioxidant compounds involved and their changes during the forcing process. The properties verified so far point out that this chicory can be considered an interesting and healthy vegetable for the consumer, also after the forcing process. 


\section{References}

Anesini C., Ferraro G.E., Filip R. (in press). Total polyphenol content and antioxidant capacity of commercially available tea (Camelia sinensis) in Argentina. J. Agric. Food Chem. http://www.alimentosargentinos.gov.ar/infusiones/docs/Tea_JAFC.pdf

Benzie I.F.F., Strain J.J. 1996. The ferric reducing ability of plasma (FRAP) as a measure of "Antioxidant Power": The FRAP essay. Anal. Biochem., 239:70-76.

Cao G., Sofie E., Prior R.L. 1997. Antioxidant and prooxidant behavior of flavonoids: structure-activity relationship. Free Rad. Biol. Med., 22:749-760.

Carnovale E., Marletta L. 2009. Banca Dati di Composizione degli Alimenti INRAN. http://www.inran.it/ servizi_cittadino/per_saperne_di_piu/tabelle_composizione_alimenti/composizione/verdure.

Diaz M.N., Frei B., Vita J.A., Keancy J.F. 1997. Antioxidants and artherosclerotic heart disease. N. Eng. J. Med., 337:408-416.

Dillard C.J., German J.B. 2000. Phytochemicals: nutraceuticals and human health. Journal of the Science of Food and Agriculture, 80:1744-1756.

Francke A., Majkowska-Gadomska J. 2008. Effect of planting date and method on the chemical composition of radicchio heads. J. Elementol., 13, 2:199-204.

Giacosa A., Filiberti R., Hill M.J., Faivre J. 1997. Vitamins and cancer chemioprevention. Eur. J. Cancer Prev., 6:S47-S54.

Innocenti M., Gallori S., Giaccherini C., Ieri F., Vincieri F.F., Mulinacci N. 2005. Evaluation of the phenolic content in the aerial parts of different varieties of $\mathrm{Ci}$ chorium intybus L. J. Agric. Food Chem., 53:64976502.

Kang H.M., Saltveit M.E. 2002. Antioxidant capacity of lettuce leaf tissue increases after wounding. J. Agric. Food. Chem., 50:7536-7541.

Larrosa M., Llorach R., Espín J.C., Tomás-Barberán F.A. 2002. Increase of antioxidant activity of tomato juice upon functionalisation with vegetable byproducts extracts. Lebensm. Wiss. Technol., 35:532-542.

Lavelli V. 2008. Antioxidant activity of minimally processed red chicory (Cichorium intybus L.) evaluated in xanthine oxidase-, myeloperoxidase-, and diaphorase-catalyzed reactions. J. Agric. Food Chem., 56:7194-7200.

Llorach R., Tomás-Barberán F.A., Ferreres F. 2004. Lettuce and chicory byproducts as a source of antioxidant phenolic extracts. J. Agric. Food. Chem., 52:51095116.
Mazza G., Miniati E. 1993. Anthocyanins in Fruits, Vegetables and Grains. CRC Press, Boca Raton, FL.

Miller E.R., Appel L.J., Risby T.H. 1998. Effect of dietary patterns on measures of lipid peroxidation: result from a randomized clinical trial. Circulation, 98:2390-2395.

Nicoletto C., Pimpini F. 2009. Influence of the forcing process on some qualitative aspects in radicchio "Rosso di Treviso tardivo" (Cichorium intybus L., group rubifolium). 1. Nitrate, nitrite and organic nitrogen. Ital. J. Agron./Riv. Agron., 4:137-145.

Ninfali P., Mea G., Giorgini S., Rocchi M., Bacchiocca M. 2005. Antioxidant capacity of vegetables, spices and dressings relevant to nutrition. British Journal of Nutrition, 93:257-266.

Papetti A., Daglia M., Grisoli P., Dacarro C., Gregotti C., Gazzani G. 2006. Anti- and pro-oxidant activity of Cichorium genus vegetables and effect of thermal treatment in biological systems. Food Chemistry, 97:157-165.

Pimpini F. 1990. Radicchio. In: Pimpini F., Bianco V.V. (eds.): Orticoltura, 320-338. Patron Ed., Bologna, Italy.

Reyes L.F., Villareal J.E., Cisneros-Zevallos L. 2007. The increase in antioxidant capacity after wounding depends in the type of fruit or vegetable tissue. Food Chemistry, 101:1254-1262.

Rice-Evans C.A., Miller N.J., Paganga G. 1997. Antioxidant properties of phenolic compounds. Trends in Plant Science, 2, 4:152-159.

Shao H., Chu L., Shao M., Cheruth A.J., Mi H. 2008. Higher plant antioxidants and redox signaling under environmental stresses. C. R. Biologies, 331:433-441.

Shetty K., McCue P. 2003. Phenolic antioxidant biosynthesis in plants for functional food application: integration of systems biology and biotechnological approaches. Food Biotechnology, 17:67-97.

Singleton V.L., Rossi I.A. 1965. Colorimetry of total phenolics with phosphor-molybdic-phosphotungstic acid reagents. Am. J. Enol. Viticult., 16:144-158.

Stojceska V., Ainsworth P., Plunkett A., Ibanoğlu E. 2008. Cauliflower by-products as a new source of dietary fibre, antioxidants and proteins in cereal based ready-to-eat expanded snacks. Journal of Food Engineering, 87:554-563.

Vinson J.A., Hao Y., Su X., Zubik L. 1998. Phenol antioxidant quantity and quality in foods: vegetables. J. Agric. Food Chem., 46:3630-3634.

Yamakawa O., Yoshimoto M. 2002. Sweetpotato as food material with physiological functions. Acta Hort., 583:179-185. 